\title{
A ORIENTAÇÃO SEXUAL NO CONTEXTO INCLUSIVO: UM ESTUDO TEÓRICO
}

\author{
ANDREZA MARQUES DE CASTRO LEÃO ${ }^{1}$ \\ PAULO RENNES MARÇAL RIBEIRO
}

\begin{abstract}
RESUMO
O intuito do presente estudo é esboçar e refletir a questão da orientação sexual no cenário inclusivo. As fontes deste trabalho são artigos, dissertações, teses e livros que versam sobre os temas da inclusão e sexualidade, aspectos estes inter-relacionados e indissociáveis. $\mathrm{O}$ assunto da sexualidade é um dos muitos que pode facilitar o processo de inclusão das pessoas com deficiências, pois está associada muito mais com o trabalho de expressão de sentimentos, atitude e de formação de valores morais, do que com conteúdos acadêmicos e científicos a ser dominado intelectualmente pelos alunos. Deste modo, a inserção da orientação sexual no contexto escolar decorre da necessidade de se propiciar uma educação geral dos alunos, a qual inclua a sexualidade. Os alunos detentores dos seus direitos precisam ter oportunidades de saber sobre a sexualidade, de modo que tenham acesso às informações precisas que envolvam este tema, a fim de que não sejam reféns dos mitos e tabus. Para o êxito da inclusão dos alunos com deficiências implica em se considerar a sexualidade, visto que é uma necessidade básica do ser humano. Portanto, é mister políticas públicas e programas educacionais eficazes, que se atenham à relevância da orientação sexual ser efetivada no cenário escolar, de modo que todos estudantes inseridos nos bancos escolares possam desfrutar de uma educação inclusiva, a qual não exclua, mas sim inclua a sexualidade.
\end{abstract}

Palavras-chave: Inclusão; orientação sexual; sexualidade; deficiências.

\section{INTRODUÇÃO}

O intuito do presente estudo é esboçar e refletir a questão da orientação sexual para o contexto inclusivo. Inicialmente será apresentada a temática da inclusão escolar, após, será discutida a relevância da inserção da sexualidade. Em seguida, será explicitado o porquê da orientação sexual ser direcionada a todos os alunos.

\footnotetext{
${ }^{1}$ Núcleo de Estudos da Sexualidade - Faculdade de Ciências e Letras - Universidade Estadual Paulista -14.800-901 Araraquara SP. E-mail: andreza leao@yahoo.com.br

${ }^{2}$ Núcleo de Estudos da Sexualidade - Faculdade de Ciências e Letras - Universidade Estadual Paulista -14.800-901 Araraquara SP. E-mail: paulorennes@fclar.unesp.br
} 
O presente estudo é de natureza teórica. O estudo teórico é definido nas palavras de Oliveira (1998, p. 23) como sendo: “ampliar generalizações, relacionar e enfeixar hipóteses numa visão mais unitária do universo e gerar novas hipóteses por dedução lógica."

Assim sendo, as fontes deste trabalho são artigos, dissertações, teses e livros que versam sobre os temas da inclusão e sexualidade, aspectos estes inter-relacionados e indissociáveis, sendo deste modo, relevantes de serem problematizados.

\section{DESENVOLVIMENTO}

A escola é um dos locais mais eficazes para transformar a realidade da exclusão social, e para se construir uma sociedade mais justa e igualitária, na qual todos, sem exceção, possam gozar os mesmos direitos e oportunidades. Além disso, como aponta Reily (2005) a escola é um centro rico em diversidades sócio-culturais, e mesmo com as condições adversas do contexto econômico-político-ideológico no qual está inserida, apresenta função específica, a qual deve possibilitar a apropriação do saber por todos os cidadãos.

Nesta perspectiva, a educação inclusiva é uma questão de direitos humanos, e se insere na perspectiva de assegurar a educação de qualidade para todos. Assim, a inclusão se baseia no ideário do compromisso com a cidadania e com a formação de uma sociedade democrática, não

excludente. À luz deste novo entendimento, a escola precisa estar aberta a todos os alunos, de modo que o ensino ministrado seja direcionado a todos, sejam estes deficientes ou não.

No cenário educacional desde a década de 90 do século XX, a inclusão das pessoas deficientes vem sendo alvo de inúmeras implicações, promovendo uma série de discussões nos setores acadêmicos e institucionais. Os debates desta temática foram intensificados com a Declaração de Salamanca (BRASIL, 1994), a qual realçou o direito de todas as crianças serem incluídas no sistema educacional, ou seja, "a educação para todos", servindo como norteadora para a implementação da proposta inclusiva.

Nota-se uma tendência geral desta declaração pela valorização de princípios da educação inclusiva, valorização da diferença e da diversidade como essenciais para construção de uma escola democrática. Contudo, como menciona Reily (2005), historicamente a escola tem 
dificuldade de aceitar as diferenças presentes em sala de aula. Tal fato trouxe reflexos negativos na luta das pessoas com deficiências, nos aspectos de inclusão social e dos direitos da cidadania.

O que se torna fundamental na abordagem das políticas públicas pensadas a partir dos pressupostos éticos da inclusão social é o princípio democrático da educação enquanto exercício da cidadania, entendendo-se que esta se efetiva mediante a ação concreta do Estado na garantia dos direitos e a ação dos indivíduos na sociedade (DUTRA, 2006).

O conceito do direito revela que a mera existência das leis não garante a cidadania, nem que os direitos das pessoas com deficiências serão respeitados (RIBEIRO, 2006). Todavia, Prieto (2003) propõe que para a efetivação da proposta da inclusão é preciso que os direitos já assegurados ultrapassem o plano do meramente instituído legalmente pela conquista de uma educação escolar eficaz para todos os estudantes, capaz de garantir a permanência na escola e aceitação destes indivíduos pela mesma, tendo o objetivo de minimizar a exclusão social e educacional tão marcante na atual conjuntura nacional.

Nesse sentido o direito à igualdade tem a ver com acesso na rede pública de ensino e com o estabelecimento de políticas para equiparação de oportunidades, de forma a considerar a diversidade como elemento norteador para a igualdade no processo educacional (DUTRA, 2006, p. 70).

A despeito do direito das pessoas com deficiências, a inclusão delas é muito mais do que a mera inserção no ambiente escolar. Refere-se à oportunidade de vivência plena do exercício da cidadania em diferentes contextos (escolar, familiar, entre outros), e isto inclui a oportunidade de vivenciar sua sexualidade.

Diante da necessidade de se promover uma sociedade dita "inclusiva" surgiram as propostas da reformulação do sistema educacional, a fim de adequá-lo às demandas escolares. Dentre as inovações pode-se citar os chamados "Parâmetros Curriculares Nacionais" (PCNs) (BRASIL, 1997), que se constituem num conjunto de documentos que apresentam as propostas de uma nova estruturação curricular para a educação, os quais contemplam o ensino de temas sociais presentes na vida cotidiana, enfocando as questões da cidadania, entre estas, a sexualidade.

Segundo Maia (2004, p. 164) os PCNs são constituídos por um conjunto de propostas educativas, que visam "apontar as metas de qualidade que ajudem o aluno a enfrentar o mundo atual como cidadão participativo, reflexivo e autônomo, conhecedor de seus direitos e deveres". 
Os PCNs incitam a escola a refletir sobre o seu currículo, sobre as necessidades de sua comunidade escolar quanto a realidade de diversificar as práticas pedagógicas, pois rompem a limitação da atuação dos educadores em relação às atividades formais e ampliam um leque de possibilidade para a formação do educando (MAISTRO, 2006).

Neste contexto, o ensino da sexualidade foi incluído no currículo escolar como um tema transversal, como um assunto disperso no interior das várias áreas do conhecimento, perpassando cada uma delas, e não mais vinculado somente ao biológico.

Para Menezes e Santos (2002) a transversalidade diz respeito à possibilidade de se colocar na prática educativa uma relação entre aprender conhecimentos teoricamente sistematizados, e as questões da vida real (aprender na realidade e da realidade).

Há a menção nos PCNs quanto a relevância da inserção da Orientação Sexual no ensino regular, porém, não há a alusão quanto a importância desta orientação ser direcionada a todos os alunos, com ou sem deficiências, de modo que eles tenham acesso ao conjunto de conhecimentos socialmente elaborado e reconhecido como necessário ao exercício da cidadania.

Poppi e Manzini (1999) consideram a temática da sexualidade de grande relevância atual, considerando-se que a manifestação da sexualidade dos alunos de modo geral, sejam estes deficientes ou ditos "normais", pode se expressar em diversas situações e ambientes, sendo um destes o ambiente escolar. Já Maia (2001) complementa afirmando que é inevitável constatar que no âmbito escolar os professores, funcionários, coordenadores, entre outros, vão acabar se deparando com as questões da sexualidade dos alunos.

Contudo, como menciona Nunes (2002) a escola ao detectar algum acontecimento de ordem sexual geralmente se alvoroça, não sabendo como agir, como se estivesse diante de anomalias.

Na fala de Oliveira (2000, p. 108) " $[$ [...] as demandas educacionais relativas à sexualidade dos alunos fazem parte do contexto escolar e, mesmo quando não planejado, pode surgir espaço para a orientação sexual".

Suplicy et all. (1999, p. 11) salienta que “[...] mesmo que a escola se omita, estará acontecendo algum tipo de orientação sexual. Provavelmente repressiva, inadequada e deformadora". A autora complementa afirmando que se a escola, justamente o lugar no qual a sexualidade se manifesta como um dos maiores interesses dos alunos, se omite, o resultado é um quadro crônico de desinformação. 
Todavia, o assunto da sexualidade é um dos muitos que pode facilitar o processo de inclusão das pessoas com deficiências, pois está associada muito mais com o trabalho de expressão de sentimentos, atitude e de formação de valores morais, do que com conteúdos acadêmicos e científicos a ser dominado intelectualmente pelos alunos (FIGUEIRÓ, 2003). Ela acrescenta expondo que o trabalho de orientação sexual possibilita o repensar as atitudes das pessoas quanto às minorias, entre elas, os alunos com deficiências.

De modo geral, pode-se constatar que o tema da sexualidade é polêmico, principalmente quando justaposto ao tema da deficiência (POPPI e MANZINI, 1999). A sociedade não é condescendente com relação ao comportamento social e sexual das pessoas com deficiências (GHERPELLI, 1995). Os deficientes fogem dos parâmetros aceitos como normais, assim, há resistência em aceitar que eles usufruam livremente a sua sexualidade, ou que eles possam sentir desejos (COSTA, 2000).

Para Figueiró (2002) o significado da orientação sexual está em propiciar aos alunos conhecimentos adequados sobre as questões da sexualidade, a fim de que possam viver de forma segura e responsável a sua sexualidade. A orientação sexual deve almejar a formação das pessoas, no mesmo sentido da educação geral deve fazer (MAIA, 2001).

É fundamental que os alunos com deficiência, como os demais estudantes, tenham acesso a orientação sexual, como direito que apresentam em receber esclarecimentos e orientações de forma ética e respeitosa, de modo a auxiliá-los a exercerem a sexualidade de maneira autônoma, respeitosa e prazerosa (MAIA, 2003).

Os alunos que apresentam deficiências carecem de informações sobre a sexualidade, a fim de que possam usufruir uma vida saudável e melhor integrada à sociedade Além disso, como aponta Ribeiro (2006) pode-se considerá-los mais suscetíveis às questões sexuais, revelando a necessidade de auxilio na vivência responsável de sua sexualidade.

Para Poppi e Manzini (1999), os alunos deficientes geralmente são privados do trabalho de orientação sexual, o que ocasiona a carência de informações sobre sexualidade, a fim de que possam usufruir uma vida saudável e melhor integrada na sociedade.

A fim de que ocorra a inclusão educacional dos alunos com deficiências é preciso que não se desconsidere a sexualidade, na realidade ela precisa estar estreitamente relacionada, visto que é uma necessidade básica do ser humano, a qual não pode ser desvinculada de outros aspectos. 
Neste ponto, cabe acrescentar, porém, que não se pode ter garantia que os alunos com deficiências, que freqüentam o ensino regular, receberão orientação sexual, como sugere os PCNs (RIBEIRO, 2001). Não obstante, é viável que eles tenham acesso à orientação sexual, visto que eles têm sido vítimas de restrições "[...] em nome de uma ética sexual concebida sob o signo do temor, disfarçadas em protecionismo rigoroso e altamente paternalista” (DENARI, 2002, p 12).

O silêncio, a omissão e a falta de espaço deste tema junto à estes estudantes só contribui para a proliferação dos mitos, tabus, estigmas e preconceitos que eles terão sob sua própria sexualidade. O ser deficiente não implica em ter uma sexualidade deficiente.

Diante disso, é importante maior atenção das políticas e programas educacionais quanto a orientação sexual no ambiente escolar direcionado à todos os alunos, independente de suas especificidades educativas (MAIA, 2001; MAIA, 2005). Tais medidas podem auxiliar no despertar da necessidade que os estudantes com deficiências apresentam, como os demais, de serem orientados sexualmente, haja vista que como cidadãos apresentam o direito a esta orientação.

Para o trabalho de orientação sexual no cenário escolar é importante que haja o envolvimento dos educadores, pois eles que vão efetivar os programas e as políticas educacionais junto aos alunos. Logo, se faz necessário que tenham preparo para saber lidar com as diferentes questões que terão de abarcar neste trabalho.

Costa (2000) corrobora que o desafio é interromper o processo de exclusão para poder dar início a um novo caminho, no qual possa se debater os preconceitos, limitações impostas pela deficiência, e ainda os tabus que são criados, discutir a sexualidade na forma como se apresenta na sociedade e nas possibilidades de ser vivida.

\section{CONSIDERAÇÕES FINAIS}

A escola é o local de referência para a inclusão dos alunos com deficiências. Além disso, é vista como o ambiente apropriado para se promover à orientação sexual, pois com os PCNs há uma preocupação com a formação para a cidadania, considerando-se, dentro disso, o aspecto sexual.

Diante do exposto, pode-se constatar que a inserção da orientação sexual no contexto escolar decorre da necessidade de se propiciar uma educação geral dos alunos, a qual inclua a 
sexualidade, aspecto este inerente ao homem. Os alunos detentores dos seus direitos precisam ter oportunidades de saber sobre a sexualidade, de modo que tenham acesso às informações precisas que envolvam este tema, a fim de que não sejam reféns dos mitos e tabus. Para o êxito da inclusão dos alunos com deficiências implica em se considerar a sexualidade, visto que é uma necessidade básica do ser humano.

Entretanto, com a inclusão educacional, questiona-se se a orientação sexual será direcionada a todos os alunos, de modo que os que apresentam deficiências sejam também beneficiados, haja vista que a sexualidade é um assunto complexo, ainda mais sobreposto ao da deficiência.

Portanto, é mister políticas públicas e programas educacionais eficazes, que se atenham à relevância da orientação sexual ser efetivada no cenário escolar, de modo que todos estudantes inseridos nos bancos escolares possam desfrutar de uma educação inclusiva, a qual inclua e não exclua a temática da sexualidade. Destarte, para viabilizar tais programas é imprescindível que haja o envolvimento dos educadores, para despertar neles a importância da formação ampla dos alunos, a qual considera o aspecto sexual.

\section{REFERÊNCIAS BIBLIOGRÁFICAS}

BRASIL. Ministério da Justiça. Declaração de Salamanca e Linha de Ação sobre Necessidades Educativas Especiais. Brasília: CORDE, 1994.

BRASIL. Ministério da Educação. Secretaria de Educação Fundamental. Parâmetros Curriculares Nacionais: pluralidade cultural e orientação sexual. Brasília, v. 8, 1997.

COSTA, J. Educação inclusiva e orientação sexual. Educação inclusiva e orientação sexual. Psicologia: Ciência e Profissão, Brasília, v. 20, n.1, p. 50-57, 2000.

DENARI, F.E. Sexualidade e deficiência mental: reflexões sobre conceitos. Revista Brasileira de Educação Especial, Marília, v.8, n.1, p. 9-14, 2002.

DUTRA, C.P. Políticas públicas de inclusão e o papel da educação especial. In.: MANZINI, J. (org). Inclusão e acessibilidade. Marília: ABPEE, p. 67-77, 2006.

FIGUEIRÓ, M.N.D. Repensando a educação sexual enquanto tema transversal. Cadernos de Educação, Pelotas, n.19, p. 65-81, 2002. 
FIGUEIRÓ, M.N.D. Educação Sexual: como ensinar no espaço da escola. Anais do I Congresso de Educação Inclusiva. Faculdades Integradas de Ourinhos, SP, 29 a 31 de Maio, p. 39-58, 2003.

GHERPELLI, M.H.B.U. Diferente, mas não desigual. São Paulo: Gente, 1995.

MAIA, A.C.B. Reflexões sobre a educação escolar da pessoa com deficiência. Revista Brasileira de Educação Especial, Marília, v. 7, n.1, p. 35-46, 2001.

MAIA, A.C.B. Sexualidade e deficiências no contexto escolar. Tese (Doutorado em Educação)- Faculdade de Filosofia e Ciências, Universidade Estadual Paulista Júlio de Mesquita Filho, Marília, 2003.

MAIA, A.C.B. Orientação sexual na escola. In: RIBEIRO, P.R.M. (Org). Sexualidade e educação: aproximações necessárias. São Paulo: Arte \& Ciência, p. 153-179, 2004.

MAIA, A.C.B. Relatos de professores sobre manifestações sexuais de alunos com deficiência no contexto escolar. Interação em Psicologia, Paraná, v. 9, n.1, p. 103-116, 2005.

MAISTRO, V.L.A. Projeto de Orientação sexual na escola: seus limites e possibilidades. Dissertação (Mestrado em Ciências e Educação Matemática)- Universidade Estadual de Londrina, Londrina, 2006.

MENEZES, E.T.; SANTOS, T.H. Transversalidade. Dicionário Interativo da Educação Brasileira. São Paulo: Midiamix Editora, 2002. Disponível em:<

www.educabrasil.com.br/eb/dic/dicionario.asp?id=70> . Acesso em: 23 abr. 2007.

NUNES, M.D.F. Relação de gênero e sexualidade no contexto escolar: concepções de duas professoras do ensino fundamental. Dissertação (Mestrado em Educação Especial). Universidade Federal de São Carlos, São Carlos, 2002.

OLIVEIRA, S.L. Tratado de metodologia científica: projetos de pesquisa, TGI, TCC, monografias, dissertações e Teses. São Paulo: Pioneira, 1998.

OLIVEIRA, D.L. Sexo e saúde na escola: isto não é coisa de médico? In: Meyer, D.E.E. (Org). Saúde e sexualidade na escola: isto não é coisa de médico? Porto Alegre: Cadernos de Educação Básica, p. 97-109, 2000.

POPPI, M.A.V.; MANZINI, E.J. Concepção do professor especializado sobre a sexualidade do aluno com deficiência. In: MANZINI, E.J.; BRANCATTI, P.R. (Orgs). Educação especial e estigma: corporeidade, sexualidade e expressão artística. Marília: Unesp, p. 155-165, 1999.

PRIETO, R.G. Formação de professores para o atendimento de alunos com necessidades educacionais especiais: diretrizes nacionais para a educação básica e a educação especial. In: SILVA, S.; VIZIM, M. (Orgs). Políticas públicas: educação, tecnologias e pessoas com deficiências. Campinas: Mercado das letras, p. 35-50, 2003. 
REILY, L. Deficiência e diversidade na escola. Cd-rom da $28^{a}$ Reunião atual da ANPED. Caxambu, Minas Gerais, 2005.

RIBEIRO, H.C.F. Sexualidade e portadores de deficiência mental. Revista Brasileira de Educação Especial, Marília, v. 7, n.2, p. 11-26, 2001.

RIBEIRO, H.C.F. Direitos sexuais uma conquista para pessoas com deficiência. In.: MANZINI, J. (Org). Inclusão e acessibilidade. Marília: ABPEE, p. 51-66, 2006.

SUPLICY, M.; EGYTO, A.C.; BRANCO, C.C.; SILVA, R.C.; BOCK, S.D.; SILVA, M.C.P. Sexo se aprende na escola. São Paulo: Olhos d'Àgua, 1999. 